\title{
Afterword: The Ethics of Risk, Power, and Representation
}

\author{
Melissa Swauger
}

Published online: 21 July 2011

(C) Springer Science+Business Media, LLC 2011

In my studies of girls, I have found numerous incongruities between qualitative ethical research practices and what Institutional Review Board (IRB) policies have permitted me to do. For example, to recruit adolescent girls for a qualitative research project, I partnered with an organization in Southwestern Pennsylvania that empowers girls ages eight to eighteen through gender-specific programming. To better understand these girls' daily lives and concerns, I wanted to observe them prior to data collection. I intended to build rapport and trust among the potential participants and use our interactions to frame my focus group and interview questions. However, the IRB denied my proposal to observe girls until I had a parent's consent. Later, when recruiting girls for focus groups and interviews, I learned that some potential participants were in foster care and that I could only include these girls if I obtained consent from a biological parent. I, along with caseworkers at the organization, found it ethically questionable to attempt to locate a biological parent of foster girls because many parents were inaccessible. Gaining biological parental consent proved especially uncomfortable during the interview stages of my research when a girl in foster care asked me why I did not ask her to participate in the study. I had to tell her that I had to exclude foster children. This rejection raised the ethical concern that the marginalization she experienced as a foster child was exacerbated.

The IRB's commitment to fixed procedures and rules and its discourse about the vulnerability of certain populations inadvertently blocks the ability of scholars to represent girls' voices, and homogenizes youth subjects by assuming a shared familial experience, particularly that both biological parents are present and capable of consenting for their child (Swauger 2009). Too, by seeking to protect girls by empowering organizational gatekeepers and parents to make decisions on their behalf, the IRB gives more importance to parents and organizations than to young people. It does not treat youth subjects as social agents capable of making life decisions.

Since my experience with the IRB, I have had numerous conversations with other qualitative sociologists who wrestle with IRB requirements. Colleagues and graduate students tell me about the variety of strategies that they use to meet IRB requirements,

M. Swauger $(\bowtie)$

Department of Sociology, Indiana University of Pennsylvania, Indiana, PA 15701, USA

e-mail: melissa.swauger@iup.edu 
sometimes only temporarily resolving the issues. Some redesign their methodological approach. Others sneak around IRB regulations, stating, "I'll just leave it out of the protocol and see if they say anything." Many push forward with projects that are directly opposed to IRB policies.

As we busy ourselves satisfying the IRB and teaching our students to get through the process, that is, as we "orient [our] consciousness and actions in relation to institutional ethical oversight" (Taylor and Patterson 2010, p. 11), we lose opportunities to acknowledge, discuss, and confront the real ethical issues we face in our research. We must move beyond our fear of, acquiescence to, and confrontation with IRBs toward a deeper understanding of the ethical conundrums that emerge in our work.

The contributions to this special issue exemplify qualitative research that operates within general ethical goals: "to treat participants with respect, protect them from harm, and save them from embarrassing exposure" (Bosk and DeVries 2004, p. 5). Yet the contributors recognize that qualitative research is not inherently ethical because, even if our work is "harmless, our intentions are good, and our hearts pure," we are self-interested in our research endeavors, just as are scholars in other sciences (Bosk and DeVries 2004, p. 5). They point to the need to go beyond general ethical goals and develop an understanding of ethics as an ongoing process and of ethical dilemmas that arise in ways that are impossible to predict.

The contributors illustrate that ethical considerations result from uncertainty. As Sveda Brinkman (2007) states, "Ethical phenomena are vague and uncertain because ethical problems and dilemmas appear in those situations where we are uncertain about what to do. If we knew with certainty the proper course of action, then there would be no ethical problem" (p.134). Qualitative research is "messy and unpredictable" (Taylor and Patterson 2010, p. 5) and "contextual and situational" (Brinkman and Kvale 2005, p. 169). In many ways, ethical practices in qualitative research go beyond fixed institutional guidelines.

The themes that cut across these papers are deeply grounded in ongoing reflexive analyses. In each article, the authors wrestle with ethical dilemmas that could not have been anticipated in the conceptual stages of their projects. They highlight the ethical particularities that arise when researchers interact and form relationships with research participants. Moreover, in sharing how they resolved ethical dilemmas through a thoughtful process of "continual reflexive exploration," the authors show how qualitative researchers are forced to confront conundrums at all stages of their work (Hammersley 2009, p. 218). Their important contributions include analyses of ethical concerns as they relate to participant risk, power, and representation.

\section{Participant Risk}

The design of a qualitative research project requires flexibility because elements can change in the process of data collection and analysis. Ethical issues that can potentially harm or benefit participants are thus difficult to predict prior to the start of a project because "we don't know what we will find" (Bosk and DeVries 2004, p.4). A dilemma of risk arises in qualitative research because researchers must tend to ethical situations as they occur.

The contributors to this issue confront the changing dilemmas of risk as they sought to produce work that reduced oppression and gave voice to vulnerable groups. They were forced to exclude participants because of their age, consider new dangers to which their research exposed participants, take account of the implications of having their participants sign and keep consent forms, and realize that some participants who originally wanted 
anonymity and confidentiality later wanted their voices to be heard. Responding to these changing dilemmas of risk required ongoing critical reflection, empathetic concern for participants, efforts to create honest, egalitarian relationships, and a process of "ethical consciousness" and "mindfulness" (González-López 2011).

Reflecting on the ethical standards they learned in their academic training and past experience, the authors show the importance of placing participant risk at the center of their ethical concerns (González-López 2011), especially in "ethically important moment[s]" (Einwohner 2011). Although qualitative researchers cannot predict all possible risks to their participants in advance, we can seek to be "engaged and empathetic" in the process (Alexander 2010 , p. 175), to maintain a relationship of trust over time, to treat consent as a process that is reestablished on a regular basis and renegotiated at any time (Ramcharan and Cutcliffe 2001), and to work cooperatively with our participants to detect and reduce these risks.

\section{Power}

Qualitative research requires researchers to develop relationships with participants. As these are typically hierarchical, they have the potential to cause numerous ethical dilemmas. It is likely that we have higher levels of education than our participants. We also tend to set the research agenda and, therefore, dominate interactions. We generally control not only which data are collected and analyzed, but also how participants are represented in reports (Bosk and DeVries 2004; Brinkman and Kvale 2005). Typically, participants want to be accommodating and often feel privileged they are being asked to share their life stories (Alexander 2010), which gives us power to manipulate interviews and interactions, be discreet about our agendas, and convince participants to reveal information beyond their intent (Brinkman and Kvale 2005).

Resolving the ethical dilemmas related to power dynamics that arise when we form relationships with participants requires us to be explicit about our intentions, values, and positions and to seek to balance the relationships we form with participants (Munford et al. 2008). More importantly, balancing power also requires that participants feel comfortable exercising their agency and ability to "choose for themselves whether or not they want to become involved or withdraw from a research project" (Ramcharan and Cutcliffe 2001, p. 364).

The contributors address various ways to handle power dynamics in qualitative research. From the initial stages of their projects, they reflected on who and what they represented as researchers. Remaining conscious of their biographies, identities, and political agendas, they struggled with having a personal connection to their work and remaining distant enough to complete their projects. A heightened concern did not necessarily mean they achieved equal power with research participants, but it helped diminish the possibility of exploiting participants (Best 2007).

Like other qualitative researchers, the contributors conduct projects to which they feel personally and politically connected. They approached their projects aware of their biases and continuously reflected upon new biases that emerged. They did not and could not disregard the deep empathy or justice they sought for participants, and some developed relationships, sometimes long-term friendships, with participants. These feelings and the resulting relationships forced researchers to find balance between their personal connections and their work as researchers. In discussing these relationships, the contributors raised important ethical questions about their responsibilities to participants, themselves, and academic fields. 
Qualitative researchers must engage in "ethics as process" by consciously and reflexively creating and maintaining relationships with participants (Ramcharan and Cutcliffe 2001, p. 363). This requires employing an "ethics of care" or deliberately connecting with participants, having ongoing communication, and critically reflecting on our obligations to participants (Munford et al. 2008). Building solid researcher-participant relationships and seeking to equalize the power within these relationships is crucial to the successful outcomes of a research project (Munford et al. 2008).

\section{Representation}

Interpreting and reporting data can raise serious ethical considerations, as these contributors so powerfully demonstrate. The very nature of qualitative research requires us to write culture "as we critically interrogate structures and processes that shape individuals' lives and their relations with others" (Denzin 2003, p. 463-464). Qualitative researchers dominate the interpretation and dissemination stages of research. They confront real political decisions that have the power to reassert domination over the groups they study. Such ethical questions include: "How do we use data to appropriately represent study participants with proper respect?", and "Do we have an obligation to cast our participants in a positive light?" (Currier 2011). The concern for representing participants is perhaps the most significant ethical dilemma we face.

In considering the ramifications of representing sometimes marginalized populations, the contributors in this issue challenge traditional notions of confidentiality and anonymity. Some contributors observed social interactions or solicited data from people who did not consent to participate in the study and had to determine their responsibility to people who were not "legally" part of the study. In their attempt to seek justice for participants, they also found themselves needing to discuss data that could cast their participants in a negative light. Some researchers were told directly by their participants that they were being misrepresented, while others knowingly left data out of their reports because they feared the implications.

In all of these instances, the contributors consistently assessed the larger implications of their findings. They sought ways to use data appropriately without further degrading the groups with which they worked. Contributors were also careful in how they represented their participants by giving participants the opportunity to revise their stories, staying cognizant of information revealed that was too personal or too harmful to share - no matter how useful-and confirmed with participants that the researchers accurately represented them and their stories.

Norman Denzin (2003) suggests that a new politics of interpretation is emerging in the field of qualitative research that includes a commitment to representing our participants not only in descriptive ways, but also in a manner that seeks to transform our social world. These "representational ethics" raise critical questions about knowledge generation and the kinds of contributions we want to make to the lives of those we study (Currier 2011).

\section{Future Directions}

Qualitative research that "describes the routine and problematic moments and meanings in individuals' lives" is not inherently ethical (Denzin and Lincoln 2003, p. 5). Instead, ethics must be practiced consciously as part of the research process. Because researchers interact 
with participants in complex ways, ethical situations cannot be "codified or summarized" into universal rules (Brinkman 2007, p. 131). As Svend Brinkman (2007) suggests, "We cannot go on forever formulating rules for when and how to apply [ethics], for at some point we have to act" (p.131). Even then, we may have to break the rules in order to act ethically. The contributors begin to move ethical discussions beyond the controversies associated with ethical oversight toward a more important discussion of resolving ethical dilemmas as they emerge.

The concern that IRBs may undermine our work and the ethical responsibility we feel toward research participants is legitimate (Alderson and Morrow 2005). But we should be wary of getting stuck in conversations that focus on ethical oversight because in doing so, the real ethical issues we face can be obscured. What is more important is helping qualitative researchers find ways to confront ethical issues without compromising the quality of their research (Roth 2005). We can do this by continuing to acknowledge and share ethical dilemmas that stem from issues that unfold in the field. The conference organized by Kathleen Blee and Ashley Currier and the resulting special issue of Qualitative Sociology helps us move in this direction. We might also move in other directions such as forming ethics working groups for qualitative researchers at our own universities. Some scholars structure their research methods courses to include instruction on ethics, particularly the nuanced conversations that arise as we conduct research. We might also organize forums that bring together qualitative researchers, review boards, funding agencies, and researchers from other disciplines to expand ethical debates and promote consensus (Alderson and Morrow 2005). Ultimately, these new directions can and should seek to raise ethical standards in qualitative research.

\section{References}

Alderson, P., \& Morrow, V. (2005). Multidisciplinary research ethics review: Is it feasible? International Journal of Social Research Methodology, 9, 405-417.

Alexander, S. (2010). "As long as it helps somebody": Why vulnerable people participate in research. International Journal of Palliative Nursing, 16, 173-178.

Best, A. (2007). Introduction. In A. Best (Ed.), Representing youth: Methodological issues in critical youth studies (pp. 1-33). New York: New York University Press.

Bosk, C., \& DeVries, R. (2004). Bureaucracies of mass deception: Institutional review boards and the ethics of ethnographic research. The Annals of the American Academy of Political and Social Science, 595, 249-263.

Brinkman, S. (2007). The good qualitative researcher. Qualitative Research in Psychology, 4, 127-144.

Brinkman, S., \& Kvale, S. (2005). Confronting the ethics of qualitative research. Journal of Constructivist Psychology, 18, 157-181.

Currier, A. (2011). Representing gender and sexual dissidence in southern Africa. Qualitative Sociology, 34 (3).

Denzin, N. (2003). The practices and politics of representation. In N. Denzin \& Y. Lincoln (Eds.), The landscape of qualitative research: Theories and issues (pp. 458-498). Thousand Oaks: Sage.

Denzin, N., \& Lincoln, Y. (2003). Introduction: The discipline and practice of qualitative research. In N. Denzin \& Y. Lincoln (Eds.), The landscape of qualitative research: Theories and issues (pp. 1-45). Thousand Oaks: Sage.

Einwohner, R.L. (2011). Seeing clearly with double vision: Ethical considerations on the use of archived testimonies in Holocaust research. Qualitative Sociology, 34 (3)

González-López, G. (2011). Mindful ethics: Comments on informant-centered practices in sociological research. Qualitative Sociology, 34 (3)

Hammersley, M. (2009). Against the ethicists: On the evils of ethical regulation. International Journal of Social Research Methodology, 12, 211-225.

Munford, R., Sanders, J., Mirfin Veitch, B., \& Conder, J. (2008). Ethics and research: Searching for ethical practice in research. Ethics and Social Welfare, 2, 50-66. 
Ramcharan, P., \& Cutcliffe, J. (2001). Judging the ethics of qualitative research: Considering the "ethics as process" model. Health \& Social Care in the Community, 9, 358-366.

Roth, W. (2005). Ethics as social practice: Introducing the debate on qualitative research ethics. Forum: Qualitative Social Research, 6, Art. 9.

Swauger, M. (2009). No Kids Allowed!!!' How IRB ethics undermine qualitative researchers from achieving socially responsible ethical standards. Race, Gender, \& Class, 16, 63-81.

Taylor, J., \& Patterson, M. (2010). Autonomy and compliance: How qualitative sociologists respond to institutional ethical oversight. Qualitative Sociology, 33, 161-183.

Melissa Swauger is an Assistant Professor of Sociology at Indiana University of Pennsylvania. Her research interests include stratification in education and work, pubic sociology, and feminist qualitative research methods. Melissa also works with several girl-serving organizations in Soutwestern Pennsylvania. 